\title{
PEDOFILIA E ESTUPRO DE VULNERÁVEL: O CONFLITO APARENTE DE LEIS ENTRE O ESTATUTO DA CRIANÇA E DO ADOLESCENTE E O CÓDIGO PENAL
}

\author{
Eneida Orbage de Britto Taquary ${ }^{1}$ \\ Isadora Orbage de Britto Taquary ${ }^{2}$
}

Resumo: A liberdade sexual de crianças e adolescentes é protegida na legislação infraconstitucional, no Estatuto da Criança e do Adolescente, e no Código Penal de 1940. A problemática refere-se ao conflito de leis penais que tipificam condutas violadoras da liberdade sexual de crianças e adolescentes. Objetiva-se com a discussão conhecer o princípio da proteção integral; conhecer os elementos do crime de pedofilia e do estupro de vulnerável; identificar o conflito entre o Estatuto da Criança e do Adolescente e o Código Penal. A metodologia e o material utilizados para a pesquisa se concentram na legislação brasileira de caráter penal e na doutrina especializada sobre o tema.

Palavras-chave: estupro de vulnerável, pedofilia, proteção integral de crianças e adolescentes.

\section{PEDOPHILIA AND VULNERABLE STUPULT: THE APPARENT CONFLICT OF LAW BETWEEN CHILD AND ADOLESCENT STATUS AND THE PENAL CODE}

\begin{abstract}
The sexual freedom of children and adolescents is protected under infraconstitutional legislation, The Child and Adolescent Statute, and the Criminal Code of 1940. The problem refers to the conflict of criminal laws that criminalize conduct that violates the sexual freedom of children and adolescents. The objective of the discussion is to know the principle of integral protection; know the elements of the crime of pedophilia and the rape of vulnerable; identify the conflict between the Child and Adolescent Statute and the Penal Code. The methodology and material used for the research focus on Brazilian criminal law and specialized doctrine on the subject.
\end{abstract}

Keywords: rape of vulnerable, pedophilia, full protection of children and adolescents.

\section{INTRODUÇÃO}

A proteção de crianças e adolescentes está prevista no texto Constitucional, no art. 227, prestigiando o princípio da proteção integral, o que significa dizer que sempre será observado o melhor interesse da criança e do adolescente.

\footnotetext{
${ }^{1}$ Doutora em Direito e Políticas Públicas. Mestre em Direito Internacional. Mestre em Direito e Políticas Públicas. Professora de Direito Penal.

${ }^{2}$ Mestre em Direito.
}

Revista de Direito Penal, Processo Penal e Constituição | e-ISSN: 2526-0200 | Porto Alegre | v. 4 | n. 2 | p. $99-117$ | Jul/Dez. 2018 
A proteção criança e do adolescente se desdobra na Lei 8.069/1990, conhecido como Estatuto da Criança e do Adolescente- ECA, e ainda no Código Penal de 1940, com as modificações da Lei 12015/2009.

O Estatuto da Criança e do Adolescente- ECA constitui o código material e processual dos direitos e obrigações dos menores de dezoito anos, prevendo condutas criminosas que podem ser realizadas contra eles, vitimizando-os. Estabelece também a responsabilidade do Estado Brasileiro, dos pais, parentes e terceiros no trato com crianças e do adolescentes, no tocante aos seus direitos e liberdades, em especial em material sexual.

Nesta seara é que se situa o problema do artigo, porque a liberdade sexual está disciplinada no Estatuto da Criança e do Adolescente- ECA, e ainda no Código Penal de 1940, com as modificações da Lei 12015/2009, instaurando um conflito aparente de leis penais.

O conflito de leis penais que tipificam condutas violadoras da liberdade sexual de crianças e adolescentes, delimita a problemática, pois há previsão dos crimes no Código Penal e no Estatuto da Criança e do Adolescente- ECA. A pedofilia está prevista no Estatuto da Criança e do Adolescente e o estupro de vulnerável está previsto no Código Penal.

Conhecer o princípio da proteção integral; os elementos do crime de pedofilia e do estupro de vulnerável; identificar o conflito entre o Estatuto da Criança e do Adolescente e o Código Penal são objetivos da análise.

A metodologia e o material utilizados para a pesquisa se concentram na legislação brasileira de caráter penal. De um lado a análise do Estatuto da Criança e do AdolescenteECA, quanto à previsão da pedofilia, e de outro, o estupro de vulnerável, previsto no Código Penal de 1940, com as modificações da Lei 12015/2009.

A previsão, respectivamente, da pedofilia e o estupro de vulnerável, as duas condutas mais conhecidas, no Código denota falta de técnica jurídica na elaboração da lei e ocasiona uma proteção deficitária às vítimas.

Os resultados da pesquisa revelam que a legislação especial, o Estatuto da Criança e do Adolescente, não trata de todas as condutas violadoras da liberdade sexual tipificadas no 
ordenamento jurídico, que têm como vítimas crianças e adolescentes, mas estão contidas também no Código Penal Brasileiro, dificultando a aplicação da lei e a completa aplicação do princípio da proteção integral.

\section{O PRINCÍPIO DA PROTEÇÃO INTEGRAL DE CRIANÇAS E ADOLESCENTES}

O Brasil adotou o princípio da proteção integral em três momentos distintos na legislação nacional. O primeiro, no art. 227, da Constituição Federal, quando prevê o dever do Estado, da sociedade e da família de assegurar, com prioridade, à criança, ao adolescente e ao jovem "o direito à vida, à saúde, à alimentação, à educação, ao lazer, à profissionalização, à cultura, à dignidade, ao respeito, à liberdade e à convivência familiar e comunitária, além de colocá-los a salvo de toda forma de negligência, discriminação, exploração, violência, crueldade e opressão", o segundo ao elaborar o Estatuto da Criança e do Adolescente (ECA), a Lei 8.069, de 13 de julho de 1990, e o terceiro ao adotar a Convenção Internacional dos Direitos da Criança, por intermédio do Decreto $n^{\circ}$ 99710, de 21 de novembro de 1990, que disciplinou os direitos e liberdades "de todo ser humano com menos de dezoito anos de idade".

No âmbito da jurisdição doméstica, o Estatuto diferenciou crianças, que tenham até onze anos, e adolescentes, considerando aquelas pessoas que tenham até dezessete anos. $\mathrm{O}$ Estatuto consolidou o texto constitucional, acima referido, e ainda internalizou a legislação procedente do sistema onusiano, ao incluir regras no ECA extraídas da Convenção Internacional dos Direitos da Criança; o rol de direitos e liberdades, e mais importante ainda o princípio da proteção integral.

A proteção é denominada de integral em ostensiva afronta ao princípio do menor em situação irregular, que vigorou no Brasil até 1988. O menor, como eram designados as crianças e os adolescentes, eram alvo de atenção do Estado Brasileiro apenas quando abandonados ou quando infringiam a lei.

No sistema do Código de Menores, foram criados os Juizados de Menores, sendo o que o primeiro do Brasil surgiu no Distrito Federal, tendo como magistrado José Cândido 
Albuquerque Mello Mattos, instituído em 20 de dezembro de 1923, mas, implementado, efetivamente, no ano subsequente (ISHIDA, 2011). Não eram oferecidas as garantidas do devido processo legal, existindo assim, abusos aos internos, sendo a intenção demonstrada como uma "higienização social". Sendo necessária a regulamentação na seara do direito penal juvenil, foi consolidado, em 12 de dezembro de 1927, o Código de Menores, conhecido como Código de Mellos Matos, tendo em vista a participação expressiva do primeiro juiz de menores (ISHIDA, 2011).

O Código citado acima abrangia tanto o menor abandonado, como o delinquente, este com punição mais severa. Dentre a idade que poderia responder perante a justiça, era considerado entre os 14 e 18 anos de idade. As normas eram destoantes no sentido da garantia da liberdade e direitos dos adolescentes, a título de explanação cabe ressaltar a por terem a condição de abandonados, seriam internados, em uma escola de reforma, apenas pela potencial chance de cometer um delito (ISHIDA, 2011).

Nessa época, embora existisse a determinação de que deveriam ser encaminhados a instituições especializadas, a prática se mostrava diversa, sendo que o costume jurídico era a utilização de instituições prisionais de adultos, até porque não existia uma política de atendimento que estruturasse a aplicação das medidas de internação aos menores de 18 $\operatorname{anos(ISHIDA,~2011).~}$

Apresentando uma pequena diferença no local da concretização de tal medida, os que estivessem em conflito com a lei eram apresentados à escola de reforma, já para os que se encontravam como abandonados, pervertidos ou com grande potencial de ser, seriam internados em asilo, hospital ou orfanato (LIBERATI. 2012).

Cabe ressaltar a criação, em 1964, da Fundação Nacional do Bem Estar do menor (FUNABEM), e da Fundação Estadual para o Bem Estar do Menor (FEBEM), em 1976, com fins de obtenção do controle da violência por meio de instrumentos sociais (ISHIDA, 2011), e ainda do Serviço de Assistência aos Menores (SAM), que tinha como objetivo de sua criação, oferecer assistência social aos menores infratores e abandonados ou pervertidos com o supedâneo de que a melhor forma de ressocialização seria por meio da internação, tendo por conseguinte o afastamento do ambiente propenso à delinquência e à marginalização. Entretanto os objetivos das Instituições acima fracassaram. Constituíam "fábrica de monstros 
morais. Superlotado e sob regime da mais hedionda promiscuidade, a sua finalidade prática tem sido a de instituir para o vício, para a reação pelo crime, para todas as infames e misérias [...] (BRASIL. STF.1961).

A medida de internação não se afigurava, como o legislador e operadores do direito acreditavam, como de natureza curativa e de proteção aos menores que cometiam atos ilícitos, mas, sim, de privação de liberdade, como se fosse a pena retributiva ao cometimento do ato ilícito e, além disso, era aplicada, também, às crianças abandonadas, claramente, apresentando uma ofensa ao direito de ir e vir, tendo em vista, que mesmo não tendo praticado qualquer conduta em conflito com a lei, eram introduzidos no sistema penal juvenil.

Com o advento do Código de Menores em 10 de outubro de 1979, constituído na vigência da Política Nacional do Bem-Estar do Menor, implementada pela FUNABEM, destaca-se a doutrina da "situação irregular" aduzindo que a norma incidiria aos menores que apresentassem "patologia jurídico-social", englobando fatos efetuados pelo menor (atos infracionais), como de sua família (maus-tratos) ou da sociedade (abandono), estas medidas eram aplicadas a todos sem distinção (LIBERATI. 2012).

O mesmo diploma legal, em seu Art. 14, apresentava seis medidas possíveis de aplicação aos menores considerados em situação irregular: advertência; entrega aos pais ou responsável ou a pessoa idônea, mediante termo de responsabilidade; colocação em lar substituto; imposição de regime de liberdade assistida; colocação em casa de semiliberdade e internação em estabelecimento educacional, psicopedagógico, hospitalar, psiquiátrico ou outro adequado (LIBERATI. 2012).

A denominação utilizada para os menores definia a estigmatização conferida pela sociedade a eles, como integrante do sistema de controle formal, e pela legislação brasileira, que o definia como menor abandonado e delinquente.

A designação pejorativa somente seria mudada com o advento da Lei $n^{\circ} 8.069$, o denominado ECA, em 13 de julho de 1990, por influência da Convenção das Nações Unidas sobre os Direitos da Criança (1989/1997), aprovada pelo Decreto Legislativo $n^{\circ}$ 99710, de 21 de dezembro de 1990 , que trouxe em seu art. $1^{\circ}$, Parte I, o conceito de criança, como " todo 
ser humano com menos de dezoito anos de idade, a não ser que, em conformidade com a lei aplicável à criança, a maioridade seja alcançada antes ( ONU. 1989)

Ao aderir a referenciada Convenção, o Brasil adotou o sistema da proteção integral, normatizado não apenas na Constituição Federal de 5 de outubro de 1988, mas também no Estatuto da Criança e do Adolescente-ECA, Lei n. 8.069, de 13 de julho de 1990, que entrou em vigor na data de 12 de outubro de 1990, quando se comemora no Brasil, o dia da Criança, no Brasil.

A legislação referenciada encontra perfeita sintonia com a Declaração sobre os Direitos da Criança, adotada pela Assembléia Geral das Nações Unidas, em 20 de novembro de 1959; a Convenção da ONU sobre os Direitos da Criança, e ainda a Convenção Americana de Direitos Humanos. Toda a normatização internacional e nacional quebrou o paradigma da doutrina da situação irregular, difundida no Código de Menores, enalteceu o sistema da Proteção Integral, prevendo um sistema completo de direitos, liberdades e garantias às crianças e adolescentes, utilizando a medida socioeducativa privativa de internação restritivamente, aplicada somente nos casos daqueles que estejam realmente em conflito com a lei.

Observe-se, que dentre os direitos das crianças e dos adolescentes, a Constituição Federal e o Estatuto da Criança e do Adolescente estabeleceram a proteção da criança contra todas as formas de exploração ou abuso sexual, compromisso dos Estados-partes, firmado no art. 34 da Convenção das Nações Unidas sobre os Direitos da Criança.

A proteção à liberdade sexual de crianças e adolescentes está disciplinada no Código Penal e no Estatuto da Criança e do Adolescente. No Código Penal há tipificação dos crimes de estupro de vulnerável, corrupção de menores, satisfação de lascívia mediante presença de criança ou adolescente; favorecimento da prostituição ou de outra forma de exploração sexual de criança ou adolescente ou de vulnerável. No Estatuto da Criança e do Adolescente os crimes estão tipificados nos arts. 240 e seguintes, prevendo o denominado crime de pedofilia, corrupção de menores e o favorecimento da prostituição ou de outra forma de exploração sexual de criança ou adolescente ou de vulnerável.

Observa-se que o legislador pátrio prevê condutas típicas no Código Penal e no Estatuto da Criança e do Adolescente simultaneamente e com a mesma objetividade jurídica, 
dando ensejo ao que se denomina na doutrina penal de conflito aparente de leis, que tem como requisitos: um fato ou evento criminoso; a incidência de duas ou mais leis penais sobre o fato; o afastamento de uma das leis com fundamento em princípios do conflito aparente de leis; incidência de apenas uma lei sobre o fato, evitando o denominado bis in idem.

\section{A PEDOFILIA E O ESTUPRO DE VULNERÁVEL}

A corrupção sexual de crianças e adolescentes têm sido disciplinada na legislação penal brasileira, com denominações diversas, desde o Código de 1830, com penas majoradas quando a vítima era criança.

Antes da alteração do Código Penal, por intermédio da Lei $\mathrm{n}^{\circ}$ 12.015/2009 o abuso sexual era catalogado como crime contra os costumes, logo após passou a ser classificado como Crime contra a Dignidade Sexual, "uma expressão que está em sintonia com a Constituição Federal, pois ao reconhecer a dignidade humana, assegura a liberdade de escolha dos parceiros e própria relação sexual (TRINDADE.2010.P. 108)”.

Até o ano de 2009, os crimes sexuais mais graves eram o estupro e o atentado violento ao pudor, previstos respectivamente no Código Penal, nos arts. 213 e 214, e quando as vítimas eram menores de 14 anos, pessoas com deficiência mental, ou que não podiam oferecer resistência, utilizava o instituto da presunção de violência, para determinar a punição do agente, independentemente da anuência da vítima. A presunção de violência era instituto controvertido e combatido pelos garantistas no Direito Penal.

A terceira reforma dos crimes sexuais no Código Penal determinou a inclusão, dos crimes de estupro de vulnerável, alterou a tipificação da corrupção de menores, satisfação de lascívia mediante presença de criança ou adolescente; favorecimento da prostituição ou de outra forma de exploração sexual de criança ou adolescente ou de vulnerável.

Destaca-se quando da reforma dos crimes sexuais em 2009, que já havia previsão no ECA, nas suas várias formas, tipificados nos arts. 240 e seguintes, o denominado crime de pedofilia, corrupção de menores e o favorecimento da prostituição ou de outra forma de exploração sexual de criança ou adolescente ou de vulnerável. 
A previsão nos dois diplomas legais determinou o conflito aparente de normas, que é resolvido mediante a aplicação de princípios regentes do referenciado conflito.

\subsection{A pedofilia no Estatuto da Criança e do Adolescente}

A pedofilia é uma psicopatologia em que indivíduos possuem preferências e gostos por crianças, transfigurando-se a partir de abusos sexuais tanto no meio real quanto no virtual. Possui tanto caráter homossexual como heterossexual (HISGAIL. 2017.PP 11).

Tratada como uma doença, a CID (Classificação Internacional de Doenças) considera a pedofilia um transtorno quanto a preferência sexual, segundo Hisgail, uma "perversão strictu sensu, assistida pela intervenção médico-legal (2017.PP 11)”.

Sob o aspecto psicológico, a pedofilia é enquadrada como Transtorno Sexual e de Identidade de Gênero, em que abrange Disfunções Sexuais, as Parafilias e os Transtornos da Identidade de Gênero (TRINDADE.2010.PP. 31).

As disfunções sexuais não possuem conexão direta com a pedofilia, sobretudo relacionam-se a problemas com o orgasmo. Apresentam peculiaridade por "fantasias sexuais específicas, necessidades e práticas geralmente repetitivas e angustiantes”, anseios, comportamentos sexuais "recorrentes e intensos, que envolvem objetos, atividades, ou situações incomuns e causam sofrimento clinicamente significativo ou prejuízo no funcionamento social e ocupacional e em outras áreas da vida do indivíduo", dessa forma, residem na inadequação dos meios utilizados, por conseguinte na escolha de crianças para satisfação de seus desejos sexuais (TRINDADE.2010.PP. 31).

A pedofilia, segundo Trindade (P.36) "é considerada uma anomalia da escolha do objeto e, como tal, ingressa na rubrica das perversões como um comportamento sexual considerado patológico simplesmente porque se afasta da norma geral aceita pela sociedade no que diz respeito ao tipo de escolha objetal realizado".

Nessa ótica, por se tratar de uma perversão, o comportamento pedófilo dá-se por uma aberração em relação ao ato sexual natural, considerado uma patologia, com a obtenção de orgasmo a partir de objetos sexuais atípicos, fora de uma relação adulta genital heterossexual 
e. Por ser considerada uma palavra - perversão - pejorativa, é mais adequado adotar ao conceito de pedofilia o sentido de parafilia (TRINDADE.2010.PP. 37-38).

Por se tratar de uma preferência perversa por infantis, a pedofilia é considerada, no meio social e jurídico, como um crime, causando sentimento de revolta, repugnância, hostilidade e vingança (HISGAIL. 2017.P 22).

No Código Penal e no Estatuto da Criança e Adolescente não há regras específicas que abordam o termo pedofilia, mas sim casos de pedofilia que se introduzem a outros crimes como: o estupro de vulneráveis, satisfação de lascívia mediante presença de criança ou adolescente, corrupção de menores, favorecimento da prostituição ou de outra forma de exploração sexual de criança ou adolescente ou de vulnerável, dentre outros (TRINDADE.2010.P. 91).

Essa insuficiência de técnica do legislador em matéria penal sugere que pedofilia e estupro de vulnerável sejam crimes semelhantes, o que não corresponde à realidade, porque o primeiro pressupõe a corrupção da vítima por meio de práticas sexuais reais ou simuladas, ou o que se denomina de pornografia infantil.

A pornografia infantil está diretamente conectada à pedofilia e à exploração sexual, de forma que esta é condição indispensável para que o material pornográfico seja elaborado. É definida como qualquer tipo de representação gráfica, sonora ou escrita, real ou simulada de imagens de órgãos sexuais das crianças e adolescentes com finalidade sexual, cenas em que são obrigadas a interpretar $o$ ato sexual com maior naturalidade possível (TRINDADE.2010.P.100).

Para efeito de pornografia infantil, o conceito de criança se define como qualquer pessoa menor de dezoito anos de idade, independentemente da idade em que houve o consentimento sexual (TRINDADE.2010.P. 106).

A distribuição de materiais pornográficos, que era feita diretamente entre distribuidor e cliente em determinados locais, hoje, com a Internet, cujo acesso é realizado por qualquer pessoa, em qualquer lugar do mundo e horário, considerada o paraíso dos pedófilos e caminho para propagação dessas imagens, disseminou a indústria da pornografia infantil por ser 
formato de fácil comunicação e que permite agilidade na troca de conteúdos comercializados e a divulgação (TRINDADE.2010.P.P. 100-102).

A Internet proporciona contato direto com crianças e adolescentes, o que desencadeia a intenção do pedófilo em se aproximar intimamente, com vistas à obtenção de fotografias, vídeos e encontros fora da rede. A conduta do indivíduo não só configura um risco potencial ao infante, mas também gera o sustento econômico da organização criminal, quando mediante o pagamento, adquirem as imagens diretamente da criança ou por terceiros (TRINDADE.2010.P.P. 100-102).

O legislador, por intermédio de uma lei penal não incriminadora, estabelece no art. 241-E, do ECA, que a expressão "cena de sexo explícito ou pornográfica” compreende qualquer situação que envolva criança ou adolescente em atividades sexuais explícitas, reais ou simuladas, ou exibição dos órgãos genitais de uma criança ou adolescente para fins primordialmente sexuais.

O conceito acima é utilizado na integração das figuras incriminadoras que compõem o rol de crimes de pedofilia, pois a legislação não estabelece apenas uma conduta, mas várias, a partir do art. 240 até o 244-B, todos do Estatuto da Criança e do Adolescente.

A crime de pedofilia se subsume, inicialmente, no art. 240, do ECA, que tem como núcleo "produzir, reproduzir, dirigir, fotografar, filmar ou registrar, por qualquer meio, cena de sexo explícito ou pornográfica, envolvendo criança ou adolescente (BRASIL. 2018)", ou "ainda quem agencia, facilita, recruta, coage, ou de qualquer modo intermedeia a participação de criança ou adolescente nas cenas referidas acima, ou ainda quem com esses contracena (BRASIL. 2018).

O crime também se caracteriza como "vender ou expor à venda fotografia, vídeo ou outro registro que contenha cena de sexo explícito ou pornográfica envolvendo criança ou adolescente, com pena de reclusão, de 4 (quatro) a 8 (oito) anos, e multa (BRASIL. 2018)", bem como "oferecer, trocar, disponibilizar, transmitir, distribuir, publicar ou divulgar por qualquer meio, inclusive por meio de sistema de informática ou telemático, fotografia, vídeo ou outro registro que contenha cena de sexo explícito ou pornográfica envolvendo criança ou adolescente (BRASIL. 2018)", com pena de reclusão, de 3 (três) a 6 (seis) anos, e multa. 
Nas formas equiparadas, são previstas as seguintes figuras: I - assegura os meios ou serviços para o armazenamento das fotografias, cenas ou imagens de que trata o caput deste artigo; II - assegura, por qualquer meio, o acesso por rede de computadores às fotografias, cenas ou imagens de que trata o caput deste artigo", com pena de com pena de reclusão, de 3 (três) a 6 (seis) anos, e multa, pois figura equiparada ao caput do art. 241-A acima citado (BRASIL. 2018)."

No art. 241-B, o tipo prevê o "adquirir, possuir ou armazenar, por qualquer meio, fotografia, vídeo ou outra forma de registro que contenha cena de sexo explícito ou pornográfica envolvendo criança ou adolescente (BRASIL. 2018)", com pena de reclusão, de 1 (um) a 4 (quatro) anos, e multa (BRASIL. 2018)".

A simulação da "participação de criança ou adolescente em cena de sexo explícito ou pornográfica por meio de adulteração, montagem ou modificação de fotografia, vídeo ou qualquer outra forma de representação visual", também é figura típica, capitulada no art. 241C, do ECA, com pena de reclusão, de 1 (um) a 3 (três) anos, e multa (BRASIL. 2018)". Há figura típica equiparada à mencionada para "quem vende, expõe à venda, disponibiliza, distribui, publica ou divulga por qualquer meio, adquire, possui ou armazena o material produzido na forma do caput deste artigo (BRASIL. 2018)".

A art. 241-D, tipifica o aliciamento, por meio do "aliciar, assediar, instigar ou constranger, por qualquer meio de comunicação, criança, com o fim de com ela praticar ato libidinoso, sendo punido com reclusão, de 1 (um) a 3 (três) anos, e multa(BRASIL. 2018)", alcançando também o agente que: " I - facilita ou induz o acesso à criança de material contendo cena de sexo explícito ou pornográfica com o fim de com ela praticar ato libidinoso; II - pratica as condutas descritas no caput deste artigo com o fim de induzir criança a se exibir de forma pornográfica ou sexualmente explícita(BRASIL. 2018)".

Da análise da Legislação penal prevista no ECA, depreende-se que a pedofilia, sob a ótica penal, encontra-se tipificada quando se produzem dados ( filmes, registro de dados, desenhos, fotografia, ou qualquer registro) que sejam publicados ou divulgados por qualquer meio, inclusive por meio de sistema de informática ou telemático, acerca das cenas de sexo explícitas ou pornográficas envolvendo crianças e adolescentes, considerando o art. 241-E, do 
ECA, que a expressão “cena de sexo explícito ou pornográfica” compreende qualquer situação que envolva criança ou adolescente em atividades sexuais explícitas, reais ou simuladas, ou exibição dos órgãos genitais de uma criança ou adolescente para fins primordialmente sexuais. Na pedofilia, o autor não pratica ato sexual com a vítima, apenas registra. Diferentemente, com se analisa abaixo, o estuprador deve praticar com a vítima ato sexual, seja do tipo conjunção carnal (relação sexual) ou outro ato libidinoso.

\subsection{O estupro de vulnerável no Código Penal Brasileiro}

O crime de estupro de vulnerável está previsto no Titulo VI do Código Penal, no II capítulo, denominado de Crimes Sexuais contra Vulnerável. Neste Capítulo do Código Penal o legislador brasileiro considerou vulnerável, e logo fragilizado em sua condição de pessoa humana, o menor de 14 (catorze) anos ou alguém que, por sua enfermidade ou deficiência mental, não tem o necessário discernimento para a prática do ato, ou que, por qualquer outra causa, não pode oferecer resistência.

Os casos de vulnerabilidade previstos na lei penal, eram anteriormente à reforma de supracitado Título, em 2009, considerados de violência presumida, admitindo ora estupro com violência presumida ou atentado violento ao pudor com violência presumida, punindo o agente do crime como se violência ou grave ameaça fossem os modos reais de execução do crime.

O crime de estupro de vulnerável foi inovação legislativa. Previsto no art. 217-A do Código Penal, se aproxima do crime de estupro, previsto no art. 213 do mesmo diploma, porque exige o evento conjunção carnal ou a prática de qualquer outro ato libidinoso para se consumar. Todavia, não exige como no estupro, a violência ou grave a ameaça, porque a vítima é vulnerável, pela idade, pela condição física ou psíquica. As vítimas são pessoas que estão em "situação de fragilidade, moral, social, cultural, fisiológica, biológica ou em perigo (NUCCI, 2016)", não exigindo a lei a capacidade de discernimento para consentir com as relações sexuais. 
A legislação penal visa proteger a dignidade sexual do menor de 14 anos ou daquele que por enfermidade ou deficiência mental, não possuir necessário discernimento para prática do ato, ou que, por qualquer outra causa, não pode oferecer resistência, exigindo que a violência sexual seja expressa na prática da conjunção carnal - cópula vagínica, introdução de pênis na vagina -, ou na pratica de outro ato libidinoso, visando o agente outras formas de satisfação sexual, como coito anal ou oral.

O autor poderá ser qualquer pessoa que utilize a vulnerabilidade da vítima para satisfazer a sua lascívia, que não se oporá ao ato dado a sua imaturidade (menor de 14 anos), a falta de discernimento ou capacidade para consentir com um ato sexual.

O elemento subjetivo consubstancia no dolo, cuja vontade livre e consciente é dirigida à prática de conjunção carnal ou outro ato libidinoso, sendo o crime classificado como hediondo, conforme a Lei 8.072/90.

O crime de estupro de vulnerável não se confunde com a pedofilia, mas pode ser cometido em concurso material de crimes pelo agente que ao manter conjunção carnal ou praticar outro ato libidinoso com a vítima, registra o fato por meio de filmagens, fotos ou outros meios, divulgando-os ou não posteriormente. Observa-se que para se consumar o estupro de vulnerável deve haver o ato sexual com a vítima vulnerável, não exigido nas modalidade de pedofilia, tipificadas no Estatuto da Criança e do Adolescente.

Também deve se destacado que não existe previsão de estupro no Estatuto da Criança e do Adolescente, assim como não há previsão no Código Penal da pedofilia, se utilizarmos a definição legal prevista nos arts. 240 a 244, do Estatuto da Criança e do Adolescente.

A inconsistência não é aparente. A melhor técnica exigiria que figurassem no Estatuto Menorista as hipóteses criminosas contra crianças e adolescentes, retirando-as do Código Penal, evitando-se o conflito aparente de leis, às avessas, porque há na lei penal geral, o Código Penal, leis que são especiais para proteger crianças e adolescentes, inexistentes no Estatuto da Criança e do Adolescente. 
O conflito de leis determina, por intermédio de um de seus princípios basilares, o princípio da especialidade, que a lei geral fica afastada pela lei especial. Todavia, no caso em exame não é possível a aplicação da regra porque a lei especial está no Código Penal e não no Estatuto da Criança e do Adolescente.

\section{O CONFLITO APARENTE DE LEIS}

O conflito aparente de leis penais é identificado quando duas ou mais leis são incidentes sobre um único fato criminoso ou contravencional. Ele se denomina aparente, porque o direito como sistema é um todo harmônico, determinando que uma lei seja afastada por outra, mediante a utilização de princípios que são utilizados em matéria penal, mas não são exclusivos do matéria, porque podem ser utilizados em outros ramos do direito. São quatro os princípios: especialidade; consunção; subsidiariedade e alternatividade.

O princípio da especialidade, como o nome está a indicar, implica afastamento da lei geral em face da especial, por possuir esta elementos especializantes face àquela.

O princípio da consunção absorve o crime meio em face do crime fim, destacando-se que o crime meio é obrigatório para a prática do crime fim, em razão da exigência do próprio legislador, que o prevê no tipo expressamente ou implicitamente. O crime meio é sempre crime autônomo na legislação penal e pra compor o crime fim perde sua autonomia determinada pela lei.

O princípio da subsidiariedade também determina a absorção do crime fim, mas o fundamento é diverso do anterior, porque o crime meio além de ser menos grave sempre, foi escolhido pelo agente como modo de execução. Não há exigência legal de sua prática para consumação do crime fim.

Por fim, o princípio da alternatividade surge nos tipos mistos, isto é, naqueles em que há mais de um núcleo, sendo todos alternativos, de forma que o agente poderá praticar mais de uma conduta e somente responderá por um crime único. A alternância entres as condutas é determinada pelo legislador, por meio da conjunção ou. 
Para este artigo, somente é relevante a aplicação do princípio da especialidade, em face de condutas previstas tanto no Código Penal, quanto no Estatuto da Criança e do Adolescente.

\subsection{O CONFLITO APARENTE DE LEIS ENTRE O ESTATUTO DA CRIANÇA E DO ADOLESCENTE E O CÓDIGO PENAL}

Como analisado acima, o crime de estupro de vulnerável foi introduzido na legislação penal, por força da Lei 12015/2009, que tem sua origem na Comissão Mista Parlamentar de Inquérito, que investigava a prostituição infantil.

As alterações legislativas foram interessantes, mas se ressentiram de boa técnica porque além do conflito de leis provocado entre o Código Penal e no Estatuto da Criança e do Adolescente.

As mudanças legislativas de 2009 reproduzem elementos do tipo seculares, como os elementos do tipo "menores de 14 anos", no estupro de vulnerável, afastando-se da denominação utilizada nas Convenções Internacionais e na Legislação Constitucional e infraconstitucional brasileiras.

Ainda admitiu a reforma dos crimes referenciados que em determinadas figuras típicas, os maiores de 14 anos e menores de 18, ficassem desamparados, como nos crimes de corrupção de menores, previsto no art. 218, do Código Penal, que somente prevê como vítima o menor de 14 anos.

No crime denominado de Satisfação de Lascívia Mediante Presença de Criança ou Adolescente prevê como vítima o menor de 14 anos também, previsto no 218-A, deixando de proteção os menores de 14 anos.

Nas causas especiais de aumento de pena relativas aos crimes de Mediação para servir a Lascívia de Outrem e o Rufianismo o aumento somente ocorre nos casos de menor de 18 (dezoito) e maior de 14 (catorze) anos, desprezando a causa de aumento de pena nos crimes contra as crianças, quando estas são vítimas, não havendo correspondentes no Estatuto da Criança e do Adolescente. 
No caso da pedofilia e do estupro de vulnerável a impropriedade técnica também não é menor que as apontadas acima.

O estupro de vulnerável deveria estar previsto no ECA, bem como todos os crimes contra criança e adolescente, evitando a confusão de denominações como a pedofilia ou a pornografia infantil.

O princípio da especialidade, acima mencionado, também é alterado, porque a lei especial está prevista no art. 217-A do Código Penal, enquanto no ECA não há previsão, gerando confusões na tipificação do crime de pedofilia e estupro de vulnerável. Essas confusões são expressas: a) na denominação do crime, pedofilia como equivalente ao estupro de vulnerável; b) o termo criança e adolescente não é utilizado pelo legislador penal, que insiste no termo menor; c) a impropriedade de proteger apenas os adolescentes com até 13 anos, mantendo sem proteção os que possuam a época do crime 14,15,16 e 17 anos, excluindo-os, de forma arbitrária da proteção penal, que se afigura, inicialmente como inconstitucional, a luz do art. 227: "[..."] É dever da família, da sociedade e do Estado assegurar à criança, ao adolescente e ao jovem, com absoluta prioridade, o direito à vida, à saúde, à alimentação, à educação, ao lazer, à profissionalização, à cultura, à dignidade, ao respeito, à liberdade e à convivência familiar e comunitária, além de colocá-los a salvo de toda forma de negligência, discriminação, exploração, violência, crueldade e opressão".(BRASIL.2018) .

\subsection{IMPROPRIEDADES DA LEGISLAÇÃO PENAL SOBRE CRIMES SEXUAIS QUE ATINGEM CRIANÇAS E ADOLESCENTES}

A pedofilia, não raras vezes é confundida com o estupro de vulnerável. O nome jurídico não aparece gravado nas figuras previstas no ECA, sendo usado para significar o estupro de vulnerável.

A confusão é gerada porque os crimes sexuais contra criança e o adolescente estão disciplinados no Código Penal e no ECA. A figura mais grave está prevista no Código Penal, o estupro de vulnerável, que foi alçado a classificação de crime hediondo pela Lei 8.072/1990.

Todavia, observa-se que no ECA todos os crimes tipificados possuem como elementar a criança e o adolescente, enquanto no Código Penal, em especial no estupro somente há 
previsão de proteção, como elementos do tipo, das pessoas consideradas vulneráveis, como o menor de 14 (catorze) anos ou alguém que, por sua enfermidade ou deficiência mental, não tem o necessário discernimento para a prática do ato, ou que, por qualquer outra causa, não pode oferecer resistência.

O estupro de vulnerável implica, como já anteriormente mencionado e discutido, ocorrência do ato sexual, enquanto o termo pedofilia não adotado pela legislação é utilizado como seu equivalente no ECA, mas reportando-se à pornografia infantil, que se consuma com o registro de cenas de sexo explícitas, reais ou simuladas, nas formas tipificadas no art. 240 a 241-D, do ECA, que envolvam criança ou adolescente em atividades sexuais explícitas, reais ou simuladas, ou exibição dos órgãos genitais de uma criança ou adolescente para fins primordialmente sexuais.

Ademais, se tomarmos como pedofilia e ou corrupção todas as figuras previstas no ECA que tipificam a violação sexual de crianças e adolescentes, incluindo-se a pornografia infantil; a prostituição e a exploração sexual de crianças e adolescentes, também haverá a inversão do princípio da especialidade, porque as figuras mais graves de violação sexual de criança e adolescente não estão no ECA e sim no Código Penal, como a exploração sexual; a prostituição; e as diversas formas de corrupção.

Há, ainda, impropriedade no Código Penal ao adotar o termo menor. O ECA utiliza em consonância com instrumentos legais internacionais e nacionais o termo criança e adolescente. O termo menor, que é elemento dos tipos no Código Penal, é herança secular das Ordenações do Reino e especialmente do Código de Menores, que se apresenta anacrônico e se distancia do princípio da proteção integral, nos termos do art. 227 da Constituição Federal, porque exclui os adolescentes com mais de 13 anos, mantendo sem proteção os adolescentes que tenham 14 anos ou sejam maiores de 14 anos, excluindo-os da proteção penal, e descumprindo o preceito constitucional previsto no art. 227, acima mencionado.

\section{CONCLUSÃO}

Conclui-se que a leis penais previstas no Código Penal, referentes a violação da liberdade sexual de crianças e adolescentes, é mais severa e tipifica maior número de condutas 
criminosas, ocorrendo uma inversão da proteção, que deveria ser, na integralidade, objeto do Estatuto da Criança e do Adolescente.

A análise dos crimes contra criança e adolescente nos remete a discussão do conflito aparente de leis, porque o ECA é lei penal especial em face do Código Penal. Todavia, o princípio da especialidade é aplicado às avessas, a lei especial não pode ser aplicada porque a figura de pedofilia no ECA é genérica, e não há previsão do estupro de vulnerável.

A pedofilia, se considerada a violação sexual de crianças e adolescentes, incluindose a pornografia infantil; a prostituição e a exploração sexual de crianças e adolescentes implicaria também a inversão do princípio da especialidade, porque as figuras mais graves de violação sexual de criança e adolescente não estão no ECA e sim no Código Penal.

O tema pedofilia é controvertido, na medida em que foi definido o estupro de vulnerável no Código Penal como o mais grave crime sexual contra crianças e adolescentes, que exige o contato físico entre vítima e autor.

As outras figuras que corrompem crianças e adolescentes, como a pornografia infantil; a prostituição e a exploração sexual deveriam receber tratamento técnico mais perspicaz do legislador para serem concentradas no Estatuto da Criança e do Adolescente, e receberem denominação e elementos apropriados para facilitar a aplicação da lei e permitir a proteção das vítimas de forma efetiva.

\section{REFERÊNCIAS BIBLIOGRÁFICAS}

ALBERTON, Mariza Silveira. Violação da Infância: Crimes Abomináveis: Humilham, Machucam, Torturam e Matam. AGE: Porto Alegre, 2005.

BARROS, Guilherme Freire de Melo. Direito da Criança e Adolescente. Coleção Sinopses para Concursos. $3^{\text {a }}$ Ed. Revista, ampliada e atualizada. - Salvador BA - 2015.

BRASIL. CONSTITUIÇÃO DA REPÚBLICA FEDERATIVA DO BRASIL DE 1988. Disponível em http://www.planalto.gov.br/ccivil_03/Constituicao/Constituicao.htm. Acesso em 10.08.2018 
BRASIL. LEI N 8.069, DE 13 DE JULHO DE 1990. Dispõe sobre o Estatuto da Criança e do Adolescente. Disponível em http://www.planalto.gov.br/ccivil_03/LEIS/L8069.htm. Acesso em 10.08.2018

GRECO, Rogério. Curso de Direito Penal: parte especial, vol. III / Rogério Greco. - 9. Ed. Niterói, RJ : Impetus, 2012

HISGAIL, Fani. Pedofilia: um estudo psicanalítico. São Paulo : Iluminuras, 2017

MIRABETTE, Julio Fabrini; MIRABETTE, Renato N. Fabrini. Manual de direito penal: parte especial: arts. 121 a 234-B do CP. 27 ed. rev., e atual. São Paulo: Atlas, 2010. v. 2.

NUCCI, Guilherme de Sousa. Crimes contra a dignidade sexual: de acordo com Lei 12.015/2009. 2 ed. rev., atual e ampl. - São Paulo: Editora Revista dos Tribunais, 2010.

SILVEIRA, Margareth Lizita. Sequelas Psicológicas da Pedofilia. Revista Jurídica. Consulex. Ano VI, n. 129. maio de 2002.

TRINDADE, Jorge. BREIER, Ricardo. Pedofilia: aspectos psicológicos e penais. $2^{\circ}$ Ed. rev. Atual de acordo com a Lei no 11. 829/08 e 12.015/09.Porto Alegre: Livraria do Advogado editora, 2010. 